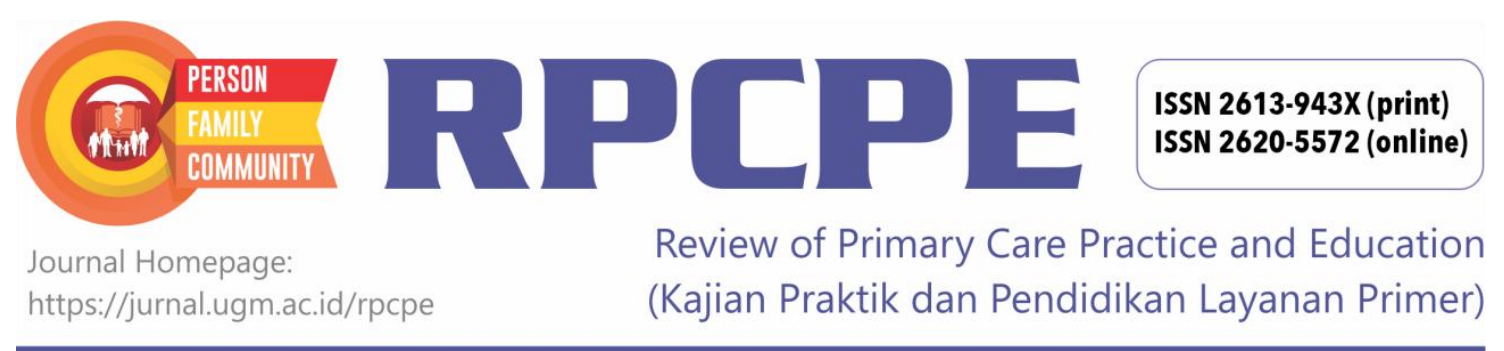

\title{
Patient-Centered Care
}

Hari Kusnanto ${ }^{1}$

\begin{abstract}
${ }^{1}$ Department of Family and Community Medicine; Faculty of Medicine, Public Health and Nursing; Universitas Gadjah Mada; Indonesia
Corresponding Author:

Hari Kusnanto: Department of Family and Community Medicine; Faculty of Medicine, Public Health and Nursing; Universitas Gadjah Mada. Gd. Radiopoetro, Lt. 1 Sayap Barat, Jl. Farmako Sekip Utara, Yogyakarta - 55281, Indonesia

Email: harikusnanto@yahoo.com
\end{abstract}

To cite this article:

Kusnanto H. Patient-centered care. Rev Prim Care Prac and Educ. 2018; 1(2): 51-52.

The healthcare system is rapidly changing with often unexpected impacts. Indonesia's national health insurance, by means of capitation payment in primary care and casebased grouping payments in advanced services ${ }^{1}$, has changed the mindset of physicians who share financial risks and must be cost conscious ${ }^{2}$. In the context of patient services constrained by cost barriers, physicians often find it unfavorable to choose an option that prioritizes patient interest. As has been the practice of physicians since Hippocrates, physicians position themselves as the one who best knows what is the most appropriate for the patient. This is in contrary to the concept of patientcentered care. Supported by the ethical principle of patient autonomy, patient-centered services/PCC (LBP/Layanan Berpusat Pasien) empower patients through the provision of more clear and accurate information, allowing patients to be partners in decision-making concerning their health. Whether PCC is truly more effective and efficient in improving patient's health status, may still require an indepth study ${ }^{3}$. PCC is different from the model that has been continuously dominating health services:

- PCC prioritizes the patient's preferences, values and objectives, rather than solely oriented toward the patient's interest in the view of the doctor or the health organization;

- PCC is based on the principle of autonomy, in contrast to the traditional medical models that prioritize the principles of beneficence and authoritarianism;

- PCC is oriented toward the patient as a human being, a bio-psycho-social being, and not merely focused on the disease;

- In PCC the outcome of the service is in accordance to what the patient wants, not just the standard treatment guidelines, protocols or clinical pathways;

- Evidence-based services which are based on the average patient's need to be supplemented by the individual patient' needs;

- PCC involves the patient in the clinical decision- making process;

- PCC takes into account the patient's experience or patient-reported outcomes.

The cultural shift and the way services are delivered to the patients must be designed, managed and rewarded financially. Patients are no longer merely customers who receive services, but partners in the process of prevention and cure of the disease. The expected benefits of patientcentered services are greater patient and family satisfaction, increased reputation of the physician or the health care provider institution, increased morale and clinical productivity of supporting staffs, and cost savings and service efficiency.

How is PCC implemented? According to the Institute of Medicine (IOM) there are six aspects to be observed ${ }^{4}$, namely 1) an appreciation of the values, preferences and needs expressed by the patient; 2) coordinated and integrated services; 3) provision of information, communication and education; 4) physical comfort guarantee; 5) provision emotional support; and 6) the involvement of family and relatives.

The Picker Institute adds two components in addition to those recommended by IOM, namely: service continuityand transition, and access to services ${ }^{5}$. The International Alliance of Patients' Organization (IAPO) outlines five PCC principles, namely: 1) respect for the unique needs, preferences and values for each patient with autonomy and freedom as fundamental rights; 2) the possibility of choosing and empowering health-care organizations to support the patient's choices; 3) patient involvementin the decision making and establishment of policy determination affecting their lives; 4) access and support to obtain needed services; and 5) provision of an accurate, relevant and comprehensive information in a format that is appropriate to the patient's condition ${ }^{6}$. 
Ideologically, PCC has the potential to improve the health of individuals and communities effectively with the involvement of patients who receive appropriate information and positive motivation to prevent and control their disease. Practically, patient-centered care principles can be used as a defense in any conflict of interest between patient groups, public policy makers and health care organizations ${ }^{7}$. The implementation of PCC in community with particular culture needs to be preceded by research on the suitability of PCC to local socio-cultural characteristics.

\section{REFERENCES}

1. Pisani E, Olivier KM, Nugroho K. Indonesia's road to universal health coverage: a political journey. Health Policy Planning. 2017 Mar 1;32(2):267-76.

2. Grover M, Abraham N, Chang YH, Tilburt J. Physician cost consciousness and use of low-value clinical services. Journal American Board Family Medicine. 2017; 29(6):785-92.

3. David G, Saynisch PA, Smith-McLallen A. The economics of patientcentered care. Journal of Health Economics. 2018;59:60-77.

4. IOM (Institute of Medicine). Crossing the quality chasm. A new health system for the 21 st century. Washington (DC). National Academic Press. 2001.

5. ACSQHC (Australian Commission on Safety and Quality in Health Care). National safety and quality health service standards, Sydney. ACSQHC. 2011.

6. IAPO (International Alliance of Patients' Organization). Patientcentered health care indicators review. Warwick, UK. IAPO. 2012.

7. Kreindler SA. The politics of patient-centered care. Health Expectation. 2015 Oct 1;18(5):1139-50. 